\title{
Fifth Asian-Pacific Congress of Cardiology
}

Singapore, as the host city to the Fifth Asian-Pacific Congress of Cardiology, 8 to 13 October, had two exceptional prerogatives. First, it is the only republic which elected as its President a surgical specialist; secondly, and this has special cardiological interest, it was in Singapore that beriberi was first successfully treated. Wenckebach, who studied the disease in Singapore, tried, unsuccessfully, the then usual antifailure treatment and also adrenaline injections, sometimes with fatal results. It was Professor E. S. Monteiro, Honorary President of the Congress, who, while studying the dietary habits of the population on the lowest subsistence level, with diarrhoea as the initial manifestation of the disease, hit upon the idea of injecting a crude extract of the discarded rice polish which led to eventual recovery.

The scientific programme included plenary sessions, symposia, and concurrent free communications. It is relevant to the present trend in cardiology that the first plenary session, chaired by Sir Kempton Maddox, dealt with prevention. Professor H. B. Wong (Singapore) considered prevention of congenital heart disease and referred to the tragic effect of an epidemic of rubella in Singapore against which the population had a low immunity. He also insisted on genetic counselling, as the risk of a second offspring being affected after a first affected child is about one in three. R. Emanuel (U.K.) in the symposium on genetics discussed the question of the heredity of idiopathic cardiomyopathy and found the name 'familial' of some clinical, but not genetic significance.

A. M. Davies (Israel) was pessimistic about rheumatic fever prevention. Improvement of living standards with avoidance of overcrowding is an unobtainable ideal; penicillin prophylaxis for streptococcal sore throat is not practicable as only 12 per cent of throat infections have a streptococcal origin and only 3 per cent of these may develop rheumatic fever. Moreover, many patients with carditis never had rheumatic fever. Penicillin prophylaxis, thus, should concentrate on prevention of progression of the heart lesion. P. Szekeley (U.K.) was of the same opinion and insisted on continuous antistreptococcal prophylaxis before development of significant valve lesion. Malignant rheumatic fever is still common in the Middle East and J. B. Borman and his colleagues (Israel) have had to replace single or double heart valves in 22 children aged 6 to 16.
The control of hypertension, on the other hand, according to Hidea Ueda (Japan), achieved a remarkable reduction in the number of strokes in Japan. He also found an epidemiological difference in the incidence of hypertension in areas of his country where the diet has a high salt, high carbohydrate, and low protein content. He was able to confirm the hypertensive effect of such a diet in rats and produced impressive slides of retinal changes in his experimental animals.

J. Stamler (U.S.A.) again confirmed the role of the much belaboured coronary risk factors (high blood pressure, cholesterol, and cigarette smoking), shown by others in free communication to be directly related to sudden death and coronary arteriosclerotic narrowing, as proved by angiocardiography. Studies of various ethnic groups of Australian aborigines (I. A. M. Prior, Australia) also substantiated that arteriosclerosis and hypertension are acquired diseases and, as such, should be preventable. Japanese, living among European communities, acquired the diseases, lacking in those in Hawaii (A. Kagan et al., U.S.A.).

The second plenary session on recent advances in coronary heart disease also mainly dealt with prevention, this time of myocardial infarction. There was some difficulty in defining 'preinfarction syndrome' for which D. G. Sloman (Australia)would prefer the term 'unstable angina' which should include 'recent', 'prolonged', and 'crescendo' angina. $\mathrm{He}$ referred to a recent paper of Fulton et al. (1972, Lancet, p. 860) which showed that only i4 per cent of these patients evolved towards myocardial infarction. W. J. Hurst (U.S.A.) also cautioned that preinfarction might include patients who have already had infarction with those who never will. $\mathrm{He}$ emphasized the importance of nocturnal angina with incipient myocardial insufficiency and the Prinzmetal type of electrocardiographic changes. According to J. F. Pantridge (N. Ireland), the best prevention is the rapid admission through mobile coronary care units, so ably organized by him in Belfast. Criteria for surgical revascularization as a prevention of myocardial infarction were considered by H. J. C. Swan (U.S.A.) as severe, disabling angina with or without previous myocardial infarction, unresponsive to medical treatment, and without cardiomegaly, and unstable angina with left main or anterior descending coronary artery stenosis, with 
or without cardiomegaly. In a subsequent symposium on acute myocardial infarction, he amplified this statement, reporting on 100 cases with cardiogenic shock. He thought that in those without cardiomegaly with occlusion of the left main or proximal anterior descending coronary artery, some perhaps with septal perforation or mitral insuffciency, surgical revascularization, even with a 40 per cent mortality, represents an improvement over medical management. M. H. Windsor (Australia) referred to 8 cases in shock saved by coronary bypass surgery or by an alternative management using diastolic augmentation with an intra-aortic balloon catheter. The latter technique was also found successful in 20 to 30 per cent of cases with cardiogenic shock as reported by Donald Ross (U.K.). W. Dudley Johnson (U.S.A.) discussed his excellent surgical results with postoperative patency in 90 per cent of aortocoronary venous bypass grafts of which to to 15 per cent may occlude during the first year but hardly any after 18 months. However, he cautioned that only long-term observations will show which of the patients may or may not benefit by operation. M. F. Oliver (U.K.) mentioned a progressive European trial which is in course and which will include 1400 randomized patients, comparing intensive medical treatment with surgical bypass where a 5 per cent operative mortality would be an acceptable risk.

In the symposium on sudden death, $M$. Oliver had some difficulty in the definition of 'sudden death' and favoured 'death within one hour of the symptoms or of last being seen alive', though such a time limit eliminated many unexpected nocturnal deaths or the ones discovered in uncommon circumstances. No recognizable preceding symptoms were found. Pathological findings (T. C. Chao, Singapore; D. Kelly, U.S.A.; J. Titus, U.S.A.) all confirmed coronary disease with or without infarction as a cause and it was shown by Kelly that sudden death was commonly associated with severe triple vessel disease and was rare in single vessel disease.

Other aspects of coronary disease were dealt with in plenary sessions, symposia, and free communications. Treatment of arrhythmias associated with myocardial infarction was a frequent subject and pacemaker insertion for symptomatic heart block with anterior infarction and bilateral bundle-branch block was accepted as treatment even if iatrogenic complications might arise (J.H. Yahini et al., Israel). Demand and bifocal demand pacing were considered by Lemberg and colleagues (U.S.A.) as the safest method to be applied in symptomatic block of any nature, particularly where atrial contribution to ventricular output was essential.

Among the many communications dealing with angina, one on nocturnal angina and sleeping stages (S. Murao et al., Japan) should be mentioned on account of continuous monitoring of electroencephalogram and electrocardiogram. They found that 70 per cent of the attacks were associated with rapid eye movement (e.g. paradoxical sleep) and occurred between 4 and 6 a.m. without acceleration of the pulse rate.

In the symposium on coronary heart disease in the young, G. Schettler and H. Greten (Germany) reported upon a multicentre trial measuring total cholesterol, beta-cholesterol in the umbilical cord blood in 1323 unselected births. They established the normal range in the newborn and re-examined their data after one year. It appears that many infants with type II hyperlipidaemia can already be diagnosed at birth and that the incidence of this abnormality is between $I$ and 8 per cent. H. Neufeld (Israel) compared the coronary arteries of the newborn in Askenazy, Yemenite, and Bedouin offspring, and found that in Askenazy male infants splitting of the intima is an early sign which becomes more obvious in childhood. These signs are almost nonexistent in Askenazy female infants and in Yemenite and Bedouin infants. P. Atlas and colleagues (Israel) analysed hyperlipoproteinaemia in young coronary patients and found primary hyperlipoproteinaemia in 80 per cent, with 50 per cent in the relatives, and stressed the importance of triglyceride assessment in type IV which can be uncovered in childhood. H. R. Casdorph U.S.A.) found cholestyramine to be the best treatment in his patients.

Operation for complications of myocardial infarction was discussed by Donald Ross (U.K.). A remarkable film by $M$. DeBakey (U.S.A.) with subsequent discussion reviewed the venous shunt operation with one to three grafts combined with gas arteriectomy in the less effective branches, with mitral and aortic valve replacement if required, and excision of akinetic and aneurysmal areas.

A plenary session was devoted to new frontiers in cardiovascular surgery. B. G. Barratt-Boyes (N.Z.) listed some of the complex cyanotic heart diseases, such as pulmonary atresia with large ventricular septal defect, truncus arteriosus, total anomalous pulmonary venous drainage, and some of the complex transpositions which may be amenable to primary surgical repair in infancy. T. Arai et al. (Japan) showed three cases of common ventricle combined with other malformations where an artificial septum was created. In the session of valve replacement, J. K. Clarebrough (Australia) reported an overall mortality of 9.4 per cent in a series of 586 aortic and mitral valve replacements, some with heterografts needing reoperation because of aortic insufficiency: about 90 per cent of the results were 
satisfactory. M. Yacoub (U.K.) advocated homograft replacements, since a new technique of graft sterilization has improved the long-term results. His comparative mortality of 3 per cent in aortic, 7 per cent in mitral, and 9 per cent in aortic and mitral valve replacement suggested an optimistic long-term outlook, using fresh, unstented homografts.

Fallot's tetralogy was the subject of another plenary session. L. H. S. van Mierop (U.S.A.) dealt with the pathological aspects and the embryology, showing how this anomaly is caused by a single embryological error. T. F. Loh et al. (Singapore) gave an account of the natural history, referring to Maurice Campbell's classic paper and confirming that survival after the age of 30 is extremely rare. The surgical aspect was considered in detail by A. Ken-ichi (Japan).

Epidemiology, conduction system, cardiac surgery in infancy with the contribution of G. Graham (U.K.) on follow-up data in operated children, pulmonary heart disease, cardiac arrhythmias, and cardiac metabolism were the subjects of other symposia and free communications. Primary myocardial disease and cardiac myopathies saw the participation of the Hammersmith team (J. F. Goodwin, C. Oakley, and E. E. J. Olsen). A new feature was the appearance of hypertrophic obstructive cardiomyopathy in infancy (J. M. Celemajer, Australia); endomyocardial biopsy ( $T$. Takatasu, Japan) in these cases shed a new light on the pathology. This technique with negligible morbidity was also reported in myxoedema heart (S. Sasayama et al., Japan) showing a mucinous substance separating muscle fibres, which disappeared after treatment. However, cardiomegaly is usually caused by pericardial effusion.

Cardiac metabolism, rehabilitation, beta-adrenergic blockers, screening methods, technical problems in cardiac surgery, to mention only a few, were other subjects dealt with by experts in Round Table Conferences. It can be said that there was no chapter of cardiology from clinical to computers that was not discussed. Except for regional problems, mainly of epidemiological interest, this congress could have taken place anywhere and proves that cardiology has similar problems both in Europe and Asia and is indivisible into continents. English as the only official language was a decisive advantage compared with European or World Congresses where bad translation often distorts a good communication.
Here, too, however there were some linguistic difficulties, mainly with the Japanese papers where the excellent slides did not compensate for the language barrier. But how many European colleagues would have the courage to present a paper in Japanese!

This sketchy and subjective report gives only a glimpse of the scientific programme of this eminently well-organized congress, the merit of which remains with Professor C. S. S. Toh and his team. There was no technical hitch with projection, the speakers kept to their allotted time, and discussions were lively. There was the inevitable overlap of subjects one would have liked to attend in the five rooms where the proceedings went on simultaneously.

The social programme was lavish and the impression was that Singapore took pride in being the host to the congress. The opening ceremony in the presence of Dr. Benjamin Henry Sheares, President of the Republic, the reception at the Istana by the Minister of Health, the final banquet with Mr. Lee Kuan Yew, the Prime Minister of Singapore, as the guest of honour, and the ample coverage in the daily press proved this. An intimate reception 'in sports shirts' was organized by the British High Commissioner for the British delegates.

Sir Kempton Maddox has resigned as President of the International Society of Cardiology and it is hoped that his kindness and charm will not be missed in future meetings as he has been re-elected as Honorary President, the effective Presidency having been taken over by Professor J. Lequime. Equally, the Presidency of the Asian-Pacific Society of Cardiology passed from Professor H. N. Neufeld to Professor Toh, the able organizer of the present Congress. Hawaii was chosen as the site of the Sixth Congress.

No report should close without mentioning the cultural show at the Victoria Theatre. Here, traditional dances, some centuries old, of the various racial communities (Chinese, Malaysian, Thai, Indian) were presented with superb art and in dazzling colours. This epitomized, in cultural respect, what we all experienced in the scientific field, the successful and harmonious co-operation of Western and Asiatic racial communities.

Cornelio Papp

Requests for reprints to Dr. Cornelio Papp, 75 Regency Lodge, Adelaide Road, London $\mathrm{NW}_{3}{ }_{5} \mathrm{~EB}$. 